\title{
Políticas públicas en el desarrollo de grandes proyectos de reconversión urbana. Caso Puerto Norte en Rosario, Argentina
}

Public policies in the development of large urban restructuring projects. The Case of Puerto Norte in Rosario, Argentina

Cecilia Inés Galimberti

\section{Resumen}

El presente artículo se propone reflexionar críticamente sobre el desarrollo de grandes proyectos de reconversión urbana, focalizando en el rol de las políticas públicas y los efectos y conflictos en torno a los mismos. Para lo cual, se toma como caso de estudio el Plan Especial de Puerto Norte en Rosario, Argentina. A través de su análisis crítico-interpretativo, se focaliza en los impactos producidos en relación a: la actualización normativa; la segregación socio-espacial; la recuperación de espacios públicos y la valoración patrimonial/identitaria. Las reflexiones resultantes de este caso contribuyen al conocimiento y al debate sobre la experiencia de Grandes Proyectos Urbanos en América Latina, especialmente en torno a la importancia del abordaje multi-actoral y multisectorial que requieren sus problemáticas complejas. Palabras clave: políticas públicas; grandes proyectos urbanos; segregación; espacio público; patrimonio.

\begin{abstract}
This article intends to critically reflect on the development of large urban restructuring projects, focusing on the role of public policies and the effects and conflicts related to them. Our case study is the Special Plan of Puerto Norte in Rosario-Argentina. Through a critical-interpretative analysis, we focus on the impacts relating to: regulatory update; sociospatial segregation; recovery of public spaces and the valuation of heritage/identity. The reflections resulting from this case contribute to knowledge of and debate on the experience of Large Urban Projects in Latin America, especially concerning the importance of the multi-sectoral and multi-actor approach that their complex problems require.
\end{abstract}

Keywords: public policies; large urban projects; segregation; public space; heritage. 


\section{Introducción}

Los cambios producidos por las nuevas dinámicas del mercado, el capital, las reestructuraciones económicas y la globalización ocasionan efectos socio-políticosterritoriales particulares en cada ámbito territorial. Especialmente en América Latina se registra un desfasaje entre las plusvalías obtenidas producto de las reconversiones urbanas y su redistribución homogénea a la sociedad. En las últimas décadas, tienden a profundizarse los espacios de desigualdad y las fragmentaciones socio-territoriales. Es decir, como explica Haesbaert (2011), se produce el agravamiento de la exclusión mediante la concentración del capital y renta, junto con la carencia de políticas públicas de redistribución efectivas. Las inversiones se vuelcan más a la especulación financiera que al sector productivo de generación de empleos y al aumento de la calidad de vida de todos los ciudadanos.

En este contexto, resulta un caso emblemático de estudio las actuaciones de re-funcionalización territorial en áreas centrales de las ciudades, como por ejemplo la realización de nuevos complejos residenciales destinados a sectores de alto poder adquisitivo en áreas correspondientes a grandes componentes productivos obsoletos. Desde fines del siglo $X X$, numerosas ciudades en todo el mundo llevan a cabo procesos de recuperación de superficies subutilizadas localizadas en áreas urbanas estratégicas, como resultan las instalaciones portuarias y ferroviarias en desuso. Estos nuevos proyectos se caracterizan por un rol predominante del mercado inmobiliario, mientras que las políticas estatales tienden a facilitar estos desarrollos que producen efectos diversos, ya sean sociales, económicos y/o territoriales.

El presente artículo plantea analizar críticamente las políticas públicas en torno a los grandes proyectos de reconversión urbana; tomando como caso de estudio el sector de Puerto Norte en la ciudad de Rosario, Argentina. El mismo abarca un área de más de 100 hectáreas que comprende instalaciones industriales, ferroviarias y portuarias localizadas estratégicamente sobre el río Paraná a inmediaciones del centro urbano de Rosario. Si bien desde mediados del siglo $\mathrm{XX}$, y reiteradamente con el transcurrir de los años, se plantea la liberación de estas infraestructuras con el fin de reinsertar este espacio a las dinámicas urbanas en nuevos usos para toda la sociedad, como la creación de parques públicos; recién comienza su reestructuración en la primera década del siglo XXI. Sin embargo, contrariamente al impulso inicial, se proyectan en estos espacios, nuevos condominios residenciales privados, edificios de oficinas y servicios comerciales destinados principalmente a sectores de alto poder adquisitivo.

En este sentido, el desarrollo de esta investigación comienza con la presentación de un breve estado de situación en el que se desarrollan los proyectos de renovación urbana en las últimas décadas, especialmente en relación al rol del mercado, las políticas públicas y los actores intervinientes. Seguidamente, se presenta el caso de estudio propuesto, a través de una síntesis de su proceso histórico de transformación, como también de las diversas políticas propuestas para el mismo a través de los años. Posteriormente, se focaliza 
en el análisis crítico-interpretativo de los efectos e impactos resultantes de este Gran Proyecto Urbano (GPU), a través del estudio particularizado de: la actualización normativa; los procesos derivados de segregación socio-espacial; la recuperación de espacios públicos y las políticas de preservación de los componentes productivos identitarios. Finalmente, se realiza una reflexión conclusiva en relación a lo expuesto, con el fin de contribuir al conocimiento y al debate sobre el desarrollo de grandes proyectos de renovación urbana, especialmente en el contexto de América Latina.

\section{El rol del mercado en la definición de políticas públicas en torno a los proyectos de renovación urbana}

Desde las últimas décadas del siglo $\mathrm{XX}$, se producen nuevas reorganizaciones territoriales vinculadas a las nuevas lógicas del capitalismo y la globalización. Diversas ciudades en todo el mundo se enfrentan en este período al desafío de la reconversión de instalaciones productivas degradadas y en desuso, mayormente localizadas en áreas urbanas centrales. Resultan ejemplo de esto, las instalaciones portuarias, ferroviarias e industriales obsoletas ubicadas en sectores estratégicos. Por lo cual, a nivel global se afrontan diversos proyectos de renovación y reutilización de estas infraestructuras, frente al gran potencial que poseen las mismas para la realización de nuevos programas.
Estos proyectos de renovación posibilitan rediseñar fragmentos del tejido y repensar el rol y la organización de toda el área que rodea al propio sector de transformación. Si bien por un lado, se permite imaginar la recuperación del acceso público a estos lugares a través del desarrollo de nuevos espacios abiertos para la comunidad. Por otro lado, también resulta un estímulo expectante para la especulación del mercado inmobiliario. Siguiendo a Carlos De Mattos (2008); existe un gran aumento de la relevancia cualitativa y cuantitativa de la inversión inmobiliaria privada en las nuevas dinámicas de las ciudades, lo que conduce a la imposición de lógicas de índole capitalista en el desarrollo urbano contemporáneo que generan cambios en las políticas públicas y en las morfologías urbano-territoriales.

Se registra así, una gran diversidad de conflictos de intereses en la realización de estos grandes proyectos, ya que existen diversas miradas contrapuestas y generalmente contradictorias entre sí. Administradores públicos, políticos, ciudadanos, empresarios, entidades económicas, entre otros, se convierten en nuevos actores clave con distintos objetivos para el destino de estas áreas.

Estos espacios tienden a ser refuncionalizados con nuevos usos, ya que en gran medida estas áreas -anteriormente productivas- son reconvertidas en nuevos ámbitos residenciales para sectores de alto poder adquisitivo, oficinas para empresas internacionales, hoteles de alto standard, entre otros. Por ejemplo, en los últimos cuarenta años, a nivel mundial se desarrollan diversos casos emblemáticos que se constituyen en referentes para otras reconversiones posteriores como resultan: los Docklands en Inglaterra, el Kop 
Van Zuid, en Rotterdam; el Baltimore Inner Harbour en Estados Unidos, el Battery Park en Nueva York, entre otros, - dentro del contexto europeo y norteamericano.

En América Latina, también son numerosas las ciudades que afrontan la reconversión urbana de diversos sectores estratégicos, como ejemplo podemos mencionar los casos de: Puerto Madero en Buenos Aires, Argentina; Rivera Norte en Concepción, Chile; Santa Fe en Ciudad de México; México; el Transmilenio en Bogotá, Colombia; Operación Urbana Faria Lima en San Pablo y Juegos Panamericanos Río 2007 en Río de Janeiro, Brasil.

En los ámbitos latinoamericanos estos grandes proyectos de renovación urbana, se desarrollan en un ámbito particular, que si bien genera oportunidades de integración internacional, también denotan desigualdades y procesos de exclusión económica y cultural.

Siguiendo a García Canclini (2008, p. 21), esto sucede en un contexto de "vaciamiento simbólico y material de los proyectos nacionales" dado el debilitamiento progresivo del Estado, especialmente desde finales de los ochenta junto a la adhesión de políticas neoliberales. Frente a las presiones del mercado global, los gobiernos nacionales tienden a resultar meros administradores de decisiones ajenas y a "atrofiar su imaginación socioeconómica y a olvidar las políticas planificadoras de largo plazo". Es decir, existe una ruptura en la relación Estadosociedad, la cual se reestructura en relación a las nuevas demandas. Según sostiene García Delgado:
[...] la relación Estado-sociedad se modifica y el Estado se reestructura en función de nuevos factores internos y externos, adoptando un paradigma ideológico o neoliberal, privilegiando la economía del mercado y los intereses de los sectores dominantes de una manera mucho más contundente que en el modelo anterior, relativamente redestribucionista. (García Delgado, 1994; apud Ciccolella, 2011, p. 16)

En este sentido, Cicolella (2011, p. 18) plantea que "el capital se transterritorializa, pero los beneficios de la reestructuración no se transocializan". Por lo cual, desde finales del siglo XX, los procesos de reestructuración económica global han influido a la transformación de la relación entre economía, sociedad y espacio. Se generan por un lado, nuevas estructuras territoriales de producción, circulación y consumo, mientras que por el otro lado, se producen nuevas formas de fragmentación socio-territorial.

Esta nueva dimensión aborda entonces profundos procesos de exclusión social, ampliando la brecha entre las funciones más valorizadas y las más degradadas, coexistente en el mismo ámbito territorial. Las mismas se desarrollan simultáneamente, a veces sin articularse, sin verse. Por un lado, grupos sociales detentadores de riqueza, considerados ciudadanos de la aldea global, y por el otro, grupos sociales excluidos, marginados. Estos efectos característicos de la ciudad dual aún pueden ser revertidos a través de la creación de políticas socio-territoriales que amortigüen los procesos que conducen a esta fragmentación (Castells e Borja, 2000). 
En Argentina, especialmente desde fines de la década de 1980, con la adhesión extrema de políticas neoliberales y la reforma del Estado se tiende a producir un desdibujamiento de los límites entre lo privado y lo público, comenzando a afirmar un modelo de ciudadanía privada basada en la auto-regulación. Estas nuevas modalidades de urbanización y de grandes proyectos de renovación en áreas centrales de las ciudades, siguiendo a Maristella Svampa (2001), se vinculan directamente con el aumento de las desigualdades sociales y la crisis del Estado para garantizar la equidad y la seguridad a todos los ciudadanos. La consolidación de estos procesos está vinculada a la concentración de la riqueza para algunos actores, mientras que otros sectores profundizan su nivel de empobrecimiento. De este modo, se ocasionan fuertes desigualdades y contrastes en la calidad de vida de la población como también se intensifica el debilitamiento de los vínculos sociales.

Estos proyectos traen consigo numerosas oportunidades de transformación para las ciudades donde se encuentran, sin embargo, para que su resultado sea exitoso, en relación al incremento de la calidad de vida de todos sus habitantes, se requiere la escucha atenta de todos los sectores de la sociedad y la articulación e integración de diversas políticas e intervenciones estratégicas. La experiencia ha demostrado, en muchos casos, que las acciones propuestas se enfocan a responder únicamente a determinados intereses económicos, a repetir modelos genéricos ya realizados en otros países, generalmente muy distintos, o a transformar estas áreas en estructuras parecidas a un parque de diversiones. Como explica Bruttomesso (1993), al visitar estas nuevas re-urbanizaciones muchas veces se está ante la presencia de un deja vu, una sensación de ya haber estado allí o de no identificar exactamente en qué parte del mundo uno se encuentra. Ya que, con el fin de obtener las mayores plusvalías posibles, tienden a realizarse operaciones de destrucción del patrimonio existente como de las marcas de identidad propias del lugar y a desencadenar, por ejemplo, procesos de gentrificación, es decir, los habitantes del sector son desplazados por otros de mayor poder adquisitivo.

Los GPU, siguiendo a Carlos Vainer (2012), también resultan intervenciones que producen e incrementan rupturas urbanas en diversos temas; por ejemplo, se producen rupturas: institucionales, políticas, urbanísticas, legales, del valor del suelo, simbólicas, escalares, entre otras. Pero las mismas presentan resultados diversos en cada proyecto particular. Por lo cual, si bien estos grandes proyectos de renovación urbana se han llevado a cabo en numerosas ciudades, es importante reflexionar sobre cómo y qué efectos producen los mismos en el ámbito local. Para lo cual es necesario discernir si estas intervenciones responden a modelos y demandas exógenas o si parten de la revalorización de la identidad local y de la escucha atenta de los reclamos de sus ciudadanos. A respecto de estas cuestiones, vamos a detenernos a continuación en el análisis de los impactos y efectos resultantes del caso de Puerto Norte en la ciudad de Rosario, Argentina. 


\section{Caso Puerto Norte de Rosario}

\section{Proceso de transformación del área de Puerto Norte: de barrio productivo a Gran Proyecto Urbano}

En Rosario, es representativo el caso de Puerto Norte, un sector ubicado estratégicamente en el frente costero de la ciudad con una extensión de más de 100 hectáreas. El mismo, desde la conformación urbana a mediados del siglo XIX, resulta un ámbito de fuerte carácter productivo, industrial, ferroviario y portuario. Debido a sus características, como la accesibilidad al río Paraná y la altura de sus barrancas, se instalan diversas industrias, por ejemplo la primera refinería de azúcar de Argentina en 1886. Este perfil productivo se consolida en los años siguientes, con nuevas instalaciones industriales ${ }^{1}$ y portuarias, consolidando un barrio obrero industrial. Dado su alto nivel de productividad, este sector requiere la conexión con el resto del país. Es así que, conjuntamente a estas industrias, se articula un complejo sistema ferroviario ${ }^{2}$ y se instalan los Talleres del Ferrocarril Central Argentino. ${ }^{3}$

Sin embargo, con el transcurrir de los años, frente al gran crecimiento que tiene Rosario, especialmente entre la segunda mitad del siglo XIX y las primeras décadas del $X X$, estas instalaciones quedan localizadas cercanas al área central de la ciudad, produciendo diversos conflictos urbanos. Por lo cual, parte de la sociedad comienza a reclamar estos espacios ribereños estratégicos para uso colectivo. De manera que, el Plan Regulador de 1952, denominado "Plan Rosario" y aprobado por Ordenanza $n^{\circ} 1.030$, propone trasladar las instalaciones del Puerto Norte hacia el sur de la ciudad. No obstante, diversas vicisitudes político-institucionales postergan dicho objetivo.

Figura 1 - Ubicación Puerto Norte en la ciudad de Rosario, Argentina

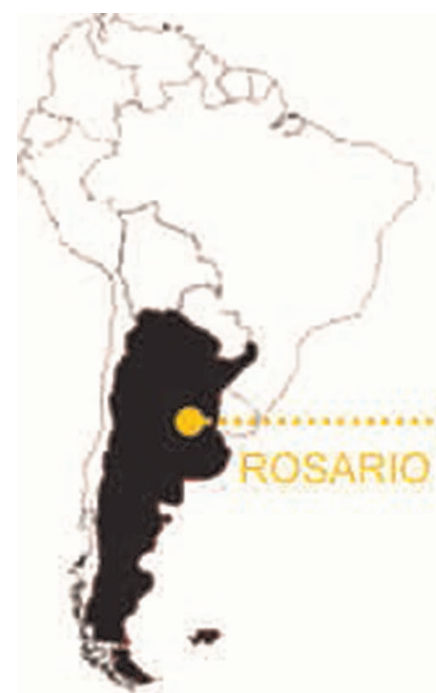

Fuente: Elaboración propia.

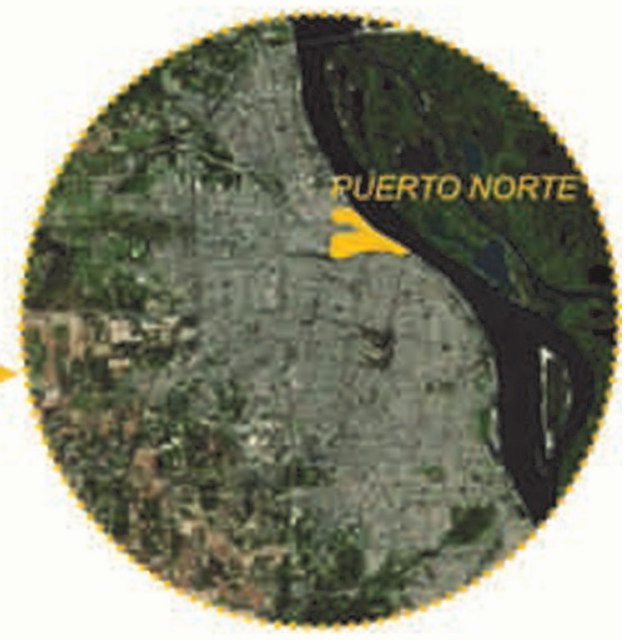


Posteriormente, esta decisión es ratificada por el Plan Regulador Rosario del año 1967. Este documento plantea "el desmantelamiento de todas las instalaciones portuarias existentes en el Área de Puerto Norte, que incluye sectores de propiedad privada también destinadas al uso portuario, reemplazándolas por nuevas instalaciones, a construir, en el Puerto Sur", a fin de recuperar "un amplio frente urbano que posibilite la parquización de espacios libres" (Municipalidad de Rosario, 1967). Asimismo, este plan propone una reestructuración ferroviaria a través de la simplificación de esas infraestructuras. De manera que, el Código Urbano, instrumento clave del Plan Regulador de 1968, identifica al área de Scalabrini Ortiz y Puerto Norte, como distrito R5, identificado como sector de reserva urbana.
Sin embargo, durante el régimen de dictadura militar entre los años 1976-1983, se suceden numerosas y diversas violaciones al Plan Regulador y al Código Urbano de 1968. Por ejemplo, en el sector de estudio, se otorgan como cesión gratuita terrenos de propiedad del Estado Nacional a firmas privadas, como Genaro García S.A., a fin de posibilitar el emplazamiento de nuevas instalaciones portuarias en este sector. También, durante este período se concreta la adquisición de la Unidad 1 del puerto por parte de la Federación Argentina de Cooperativas Agrarias - F.A.C.A, también en discrepancia con las disposiciones normativas mencionadas anteriormente.

No obstante, con el retorno democrático definitivo para Argentina, en 1983, se retoman las disposiciones de liberar este sector de

Figura 2 - Foto aérea antes del comienzo de la renovación urbana Plan Especial de Puerto Norte: Barrio Refinería, Talleres F.C.C.A, unidades productivas-portuarias Puerto Norte

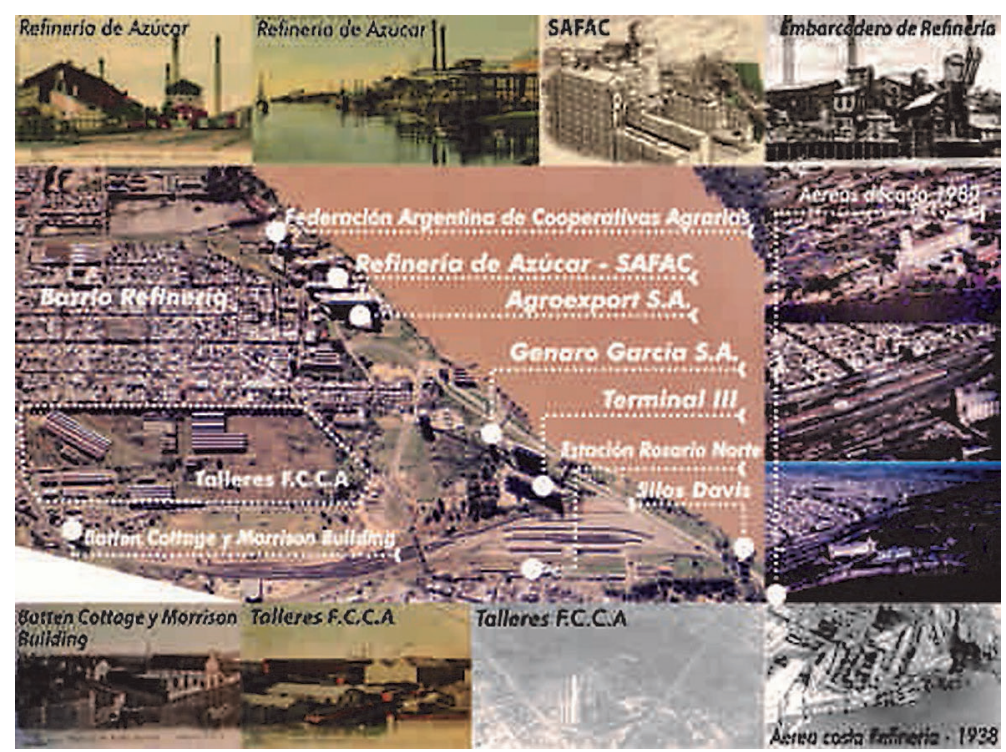

Fuente: Elaboración propia en base a archivo Secretaría de Planeamiento MR, Museo Itinerante Barrio Refinería. 
actividades productivas y se apela a recuperar dichas tierras para nuevos usos. De manera que, luego de décadas de litigio legal, se logra liberar este sector de usos productivosportuarios y se desarrolla, desde la Secretaría de Planeamiento de la Municipalidad de Rosario, un nuevo modelo de gestión y concertación público-privado a través de elaboración del Plan Especial de Puerto Norte. En el mismo se divide al sector en unidades de gestión que se proyectan en sucesivos Planes de Detalle. El proceso normativo que posibilita la reestructuración de esta zona urbana estratégica comienza a vislumbrarse en la década de 1990. La Ley Nacional de Cesión de Tierras de 1992 y el Convenio Marco entre la Municipalidad de Rosario y
Ferrocarriles Argentinos en 1996 posibilitan la ejecución de proyectos de reestructuración ferro-urbanística, a fin de avanzar en la desafectación de instalaciones y terrenos ferroviarios para su utilización en diversos proyectos urbanos.

Desde el Municipio de Rosario se propone la refuncionalización de este ámbito, para lo cual se realizan diversas fases de transformación. El primer paso de reconversión se realiza bajo el proyecto denominado "Centro de Renovación Urbana Scalabrini Ortiz", a través del programa de urbanización especial aprobada su Fase n. 1 en 1996 y su Fase n. 2 en el año 2005, por Ordenanza n. 7.892, conocida comúnmente como "Plan Especial de Puerto Norte".

Figura 3 - Primera y segunda fase Plan Especial Puerto Norte Unidades de Gestión

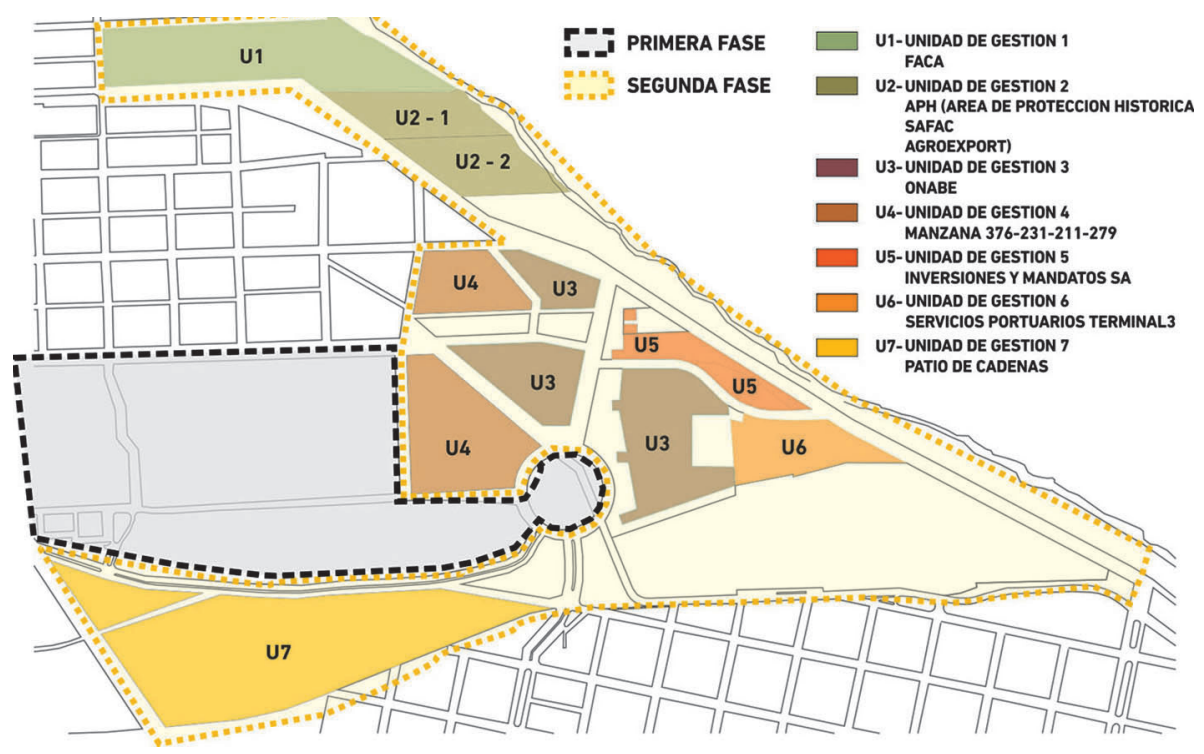


La primera fase se aprueba por la Ordenanza $n^{\circ} 6.271 / 96,{ }^{4}$ y en la misma se especifican diversos equipamientos urbanos, servicios y demás ámbitos públicos a crear, como los nuevos usos e índices edilicios permitidos. La Ordenanza $n^{\circ} 6.895 / 99$, aprueba el anteproyecto urbanístico de esta primera etapa. La segunda fase, consiste en la reestructuración de Puerto Norte, Patio Cadenas y Balanza Nueva. En la misma se define al nuevo sector de Puerto Norte como un parque poli-funcional que contemple la construcción de viviendas, parque público y edificaciones destinadas a otros usos, especialmente recreativos. Según plantea dicha normativa, la propuesta es "ofrecer un programa alternativo y complementario a los valores existentes en el área central, un lugar para los nuevos temas y no para el traslado de los existentes (...) constituir una alternativa de modernización del centro tradicional de la ciudad". ${ }^{5}$

En el año 2004, se realiza un convenio entre la Municipalidad de Rosario y el Colegio de Arquitectos de la Provincia de Santa Fe para la organización del "Concurso Nacional de Anteproyectos e ideas para la definición del Plan General para la segunda fase del Centro de Renovación Urbana Scalabrini Ortiz". En el mismo, obtiene el primer premio el equipo de

Figura 4 - Imágenes del proyecto ganador del Concurso Internacional de Ideas para Puerto Norte

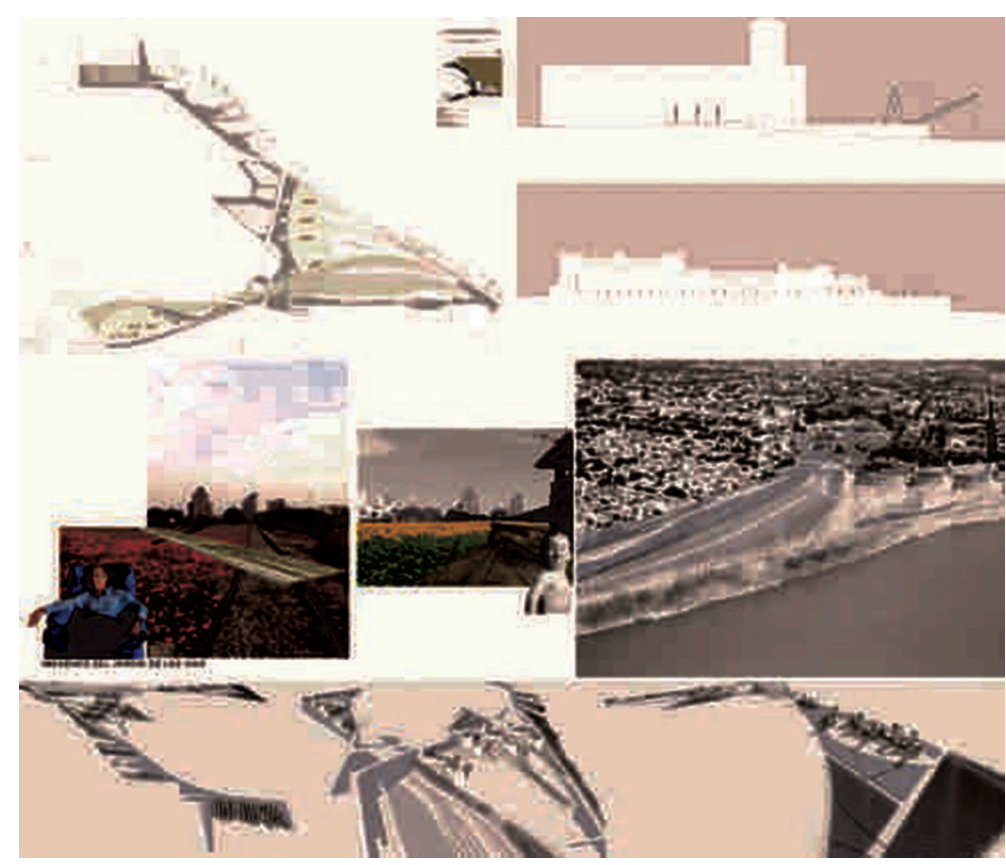

Fuente: Archivo Secretaría de Planeamiento MR. 
trabajo liderado por el Arq. Juan Munuce. La memoria descriptiva del proyecto propone:

Nos interesa construir un trozo incompleto de ciudad...un tanto defectuoso....inconcluso...que se mezcle con ese tiempo [el tiempo acumulado y con la vaguedad formal del área] sin dar demasiadas lecciones acerca de la ciudad futura. [...] Pensamos que esta arquitectura debería tener un descanso merecido, por eso solo limpiamos los medianeros de chapas oxidadas para construir el vacío necesario. [...] El edificado es concebido como un plegado que varía su altura produciendo llenos y vacíos que son patios y terrazas de casitas sobre un jardín de silos abandonados. [...] Este proyecto quiere ser un vacío sobre el vacío existente. Nos interesa construir el baldío en el baldío. Un trozo donde la ciudad se suspende alegremente para inquietar los ojos aturdidos de tanta ciudad reglada de tanta libertad vigilada... (Munuce, 2004)

El jurado de dicho concurso considera acertada la revalorización de los edificios patrimoniales propuestos, como también la permeabilidad espacial y visual que se logra según el emplazamiento de las nuevas construcciones. No obstante, plantean que existen falencias e indefiniciones, por lo cual recomiendan al municipio a profundizar y definir técnicamente esta propuesta. Sin embargo, paradójicamente, la nueva propuesta, dista ampliamente del proyecto ganador del concurso y se establecen incluso directrices opuestas a las establecidas en el mismo.
En el año 2005, a través de la Ordenanza $N^{\circ} 7.892$, se aprueba la segunda fase de esta renovación urbana. Ésta comprende tierras del Estado nacional administradas por el ONABE (Organismo Nacional de Administración de Bienes del Estado) y predios privados sujetos a reconversión, correspondiente en su mayoría a empresas cerealeras: FACA S.A., A.F.A, SAFAC S.A., Agroexport, Servicios Portuarios Unidad III, Inversiones y Mandatos S.A., Silos Minetti S.A.

Se definen así, a través de convenios público-privados nuevos indicadores urbanísticos, usos del suelo y modalidades de ocupación admitidos. Éstos se fijan en relación a las previamente definidas "Unidades de Gestión" ${ }^{6}$ El cuerpo normativo completo de Puerto Norte queda compuesto entonces, por una ordenanza básica y siete ordenanzas complementarias, vinculadas a cada unidad de gestión.

El Plan Especial de Puerto Norte se encuentra en distintas etapas de desarrollo, ya que si bien algunas unidades de gestión se encuentran finalizadas, otras están en proceso de construcción, mientras que hay unidades todavía en estudio normativo. Sin embargo, a pesar de que este gran proyecto de renovación urbana se encuentra en curso, podemos realizar diversos análisis críticos en relación a diversos impactos normativos, económicos, sociales, territoriales y materiales. De manera que a continuación, vamos a focalizar el estudio de las políticas públicas de la renovación urbana de Puerto Norte a través del análisis crítico de los siguientes temas: 
Figura 5 - Unidades de Gestión

\begin{tabular}{|c|c|c|}
\hline \multicolumn{3}{|c|}{ UNIDADES DE GESTIÓN } \\
\hline$\underset{1}{\text { UG }}$ & 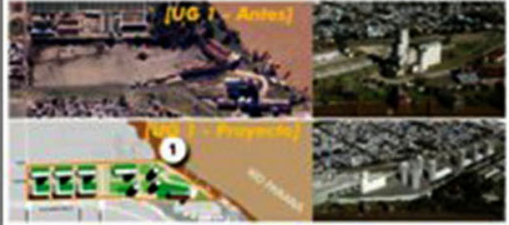 & $\begin{array}{l}\text {-Unidad de Gestión 1-Ex FACA-AFA- } \\
\left.\text { (Ordenanza } \mathrm{N}^{\circ} 8.320 / 08\right) \text { : La superficie del área es mayor a } 80.000 \\
\text { m2. Se combinan edificios de } 7 \text { y } 23 \text { pisos de altura. Según nuevos } \\
\text { indices establecidos en esta Ordenanza la superficie a edificar es } \\
\text { de } 117.000 \mathrm{~m} 2 \text {. Se debe destinar } 37.000 \mathrm{~m} 2 \text { como superficie a } \\
\text { espacio público. }\end{array}$ \\
\hline $\begin{array}{l}\text { UG } \\
2.1\end{array}$ & 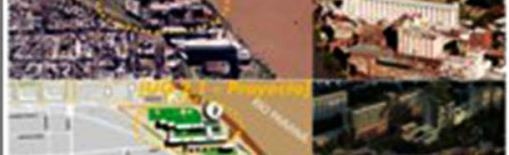 & $\begin{array}{l}\text { - Unidad de Gestión 2-Sector 1-FORUM PUERTO NORTE-Ex } \\
\text { Malteria SAFAC S.A.: } \\
\left.\text { (Ordenanza N }{ }^{\circ} 8.065 / 06\right) \text { : La superficie del predio es de } 21.030 \mathrm{~m} 2 \text {. } \\
\text { Se permite la construcción de } 68.800 \mathrm{~m} 2 \text {. }\end{array}$ \\
\hline $\begin{array}{l}\text { UG } \\
2.2\end{array}$ & & $\begin{array}{l}\text { - Unidad de Gestión } 2 \text { - Sector } 2 \text { - CIUDAD RIBERA - Ex } \\
\text { Agroexport S.A. } \\
\left.\text { (Ordenanza } \mathrm{N}^{\circ} 8.237 / 08\right) \text { : La superficie de esta unidad de gestión } \\
\text { es de } 21.592 \mathrm{~m} 2 \text {. La superficie aedificar admitida total es de } 49.253 \\
\mathrm{~m} 2 \text {. }\end{array}$ \\
\hline $\begin{array}{l}\text { UG } \\
3+7\end{array}$ & & $\begin{array}{l}\text { - Unidad de Gestión 3- ADIF-perteneciente al ex ONABE- La } \\
\text { superficie del predio comprende } 36,25 \text { Has -distribuidas en tres } \\
\text { parcelas-. Se prevé que la altura de las edificaciones variará entre } \\
13 \text { a66m. } \\
\text { - Unidad de Gestión } 7 \text { - ADIF (Ex ONABE) - se encuentra en } \\
\text { proceso de elaboración la normativa pertinente. }\end{array}$ \\
\hline$\underset{4}{\text { UG }}$ & $\frac{200}{235}$ & $\begin{array}{l}\text { - Unidad de Gestión 4- } \\
\text { Superficie del predio de } 18.205 \mathrm{~m} 2 \text {. Comprende dos partes: } \\
\text { Manzana } 279 \text {-(Ordenanza } \mathrm{N}^{\circ} 8.359 / 08 \text { ) - Comprende el desarrollo } \\
\text { de tres edificios exentos de } 18 \text { plantas y una tira de viviendas más } \\
\text { baja sobre la apertura de una nueva calle; y Manzana } 407 \\
\text { (Ordenanza } \mathrm{N}^{\circ} 8.297 / 08 \text { ) - El proyecto combina la realización de } \\
\text { edificios exentos de gran altura -una de las cuales llega a los } 66 \mathrm{~m} \text {-y } \\
\text { condominios residenciales definidos en tiras de bajas alturas. }\end{array}$ \\
\hline$\underset{5}{\text { UG }}$ & & $\begin{array}{l}\text { - Unidad de Gestión 5- Nordlink - Embarcadero - Dolfines } \\
\text { Guarani- } \\
\text { (Ordenanza } \mathrm{N}^{\circ} 7.893 / 05 \text { ) Superficie del predio de } 16.834 \mathrm{~m} 2 \text {. El } \\
\text { proyecto de esta unidad comprende tres edificios de viviendas en } \\
\text { torre de } 45 \text { pisoscada unay unedificio-Nordlink-con } 18 \text { y } 8 \text { plantas- } \\
\text { - La superficie de edificación es de } 76.000 \mathrm{~m} 2 \text {. }\end{array}$ \\
\hline $\begin{array}{c}\text { UG } \\
6\end{array}$ & 1 & $\begin{array}{l}\text { - Unidad de Gestión 6-Terminal3 (Ex Unidad III)- } \\
\left.\text { (Ordenanza } \mathrm{N}^{\circ} 8.320 / 08\right) \text { : La superficie del predio es de } \\
\text { aproximadamente } 25.000 \mathrm{~m} 2 \text {. Prevé la construcción de dos torres } \\
\text { de } 40 \text { pisos -en la remodelacióny reemplazo del silo existente-ydos } \\
\text { nuevas torres de } 130 \mathrm{~m} \text {. La superficie máxima a edificar es de } \\
81.000 \mathrm{~m} 2 \text {. }\end{array}$ \\
\hline
\end{tabular}

Fuente: Elaboración propia en base a Secretaría de Planeamiento MR. 
Actualización normativa.

Nuevos condominios privados frente a procesos de segregación social

Los GPU contemporáneos, como explica Vainer (2012), nos presentan nuevas formas innovadoras de relación entre capitales privados y gobiernos a través de las asociaciones público-privadas. No obstante, las mismas encubren conflictos duales y efectos contradictorios. Ya que, si bien este instrumento posibilita al Estado Ilevar a cabo grandes proyectos -"con una eficacia gerencial" que no podrían efectuarse, en los mismos términos, sin la participación privada; por otro lado, el rol del Estado se desdibuja frente a los intereses especulativos del mercado inmobiliario, tendiendo a posicionarse como un mero facilitador de los mismos. Por ejemplo, se conforma un nuevo espacio normativo "a medida" que genera una ruptura con el marco normativo general.

De este modo, se crean nuevas reglas particulares para estos espacios - en relación a las alturas permitidas, los índices edilicios y de ocupación del suelo, la autorización de nuevos usos, entre otros -, que generalmente carecen de un estudio particularizado respecto al entorno del sector en cuestión. Es decir, se denota la carencia de una estrategia de buffer zone a través de la cual se produzca una transición armoniosa con la regularización vigente del resto de la ciudad. Dado que, como explica Lungo:

[...] en la medida en que los grandes proyectos urbanos no se articulen a una estrategia para el conjunto de la ciudad, se pueden generar consecuencias negativas de distinta índole, e introducir mayores distorsiones en el siempre contradictorio funcionamiento del mercado de tierra urbana al nivel general. (Lungo, 2005, p. 56)

En este sentido, la Secretaría de Planeamiento de la Municipalidad de Rosario, desarrolla diversos instrumentos particularizados para llevar a cabo proyectos específicos de renovación urbana. En Puerto Norte, se aplica la figura de Plan Especial, definido como el "instrumento técnico para programar la transformación física y funcional que se propone para un determinado sector de la ciudad", que se aplica para la "reconversión de grandes áreas urbanas que se encuentran desafectadas de su uso original o vacantes de uso" (Municipalidad de Rosario, 2011). A través de este instrumento, se establecen indicadores diferenciales al resto de la ciudad para reconvertir esta área desafectada de su uso original y definir nuevas directrices para su reurbanización.

Debido a que la propiedad de la tierra en este sector corresponde tanto a actores públicos como privados, se aplican instrumentos de gestión para la concertación, especialmente bajo la figura de los Convenios Urbanísticos. ${ }^{7}$ Ésta figura normativa resulta el medio a través de la cual se establece el acuerdo entre la Municipalidad de Rosario y los actores privados para la reconversión de dichos predios, sectorizados en unidades de gestión.

Este acuerdo se encuentra íntimamente asociado a la rentabilidad del suelo, al rol de los promotores inmobiliarios y a la tendencia de las políticas públicas a ser reguladas bajo lógicas empresariales. Según explica Cuenya (2012), se registra un nuevo paradigma empresarial en el sector público, frente a 
las asociaciones entre actuaciones públicas e inversiones privadas, dado que se tiene como objetivo la atracción de promotores para financiar el desarrollo urbano, generar ventajas competitivas y asegurar una imagen atractiva de la ciudad a fin de crear nuevas estrategias de marketing urbano. El Estado, entonces, se encuentra influenciado por las lógicas del sector privado y a través de diversos instrumentos propone obtener parte de los beneficios de rentabilidad que sus regulaciones normativas e inversiones contribuyen a generar. En palabras de Cuenya:

Conceptualmente la noción de nueva política urbana del gobierno local sintetiza los nuevos ingredientes que adquieren particularmente las políticas de regeneración urbana en las últimas décadas: por un lado, un fuerte apoyo estatal al capital privado para la revitalización de la ciudad, en donde ésta aparece como "negocio". Por otro lado, un régimen político urbano en el cual los intereses públicos y privados se amalgaman para definir las decisiones de gobierno. (2012, p. 35)

En este sentido, estos grandes proyectos de renovación urbana resultan medios de generación de plusvalías urbanas, ${ }^{8}$ en los cuales el Estado cumple un rol central. Por un lado, éste suele ser propietario, al menos en parte como ocurre en Puerto Norte, de los grandes sectores a refuncionalizar. Por el otro, como ya mencionamos, es el encargado de establecer nuevos indicadores normativos que inciden en gran medida en los cambios de valorización del suelo. Asimismo, también el Estado es el responsable de la realización de obras e infraestructuras que contribuye a la valorización progresiva de estas áreas. Por lo cual, éste también demanda beneficiarse de las plusvalías resultantes.

No obstante, como señala Cuenya (2009), generalmente los mecanismos que dispone el Estado para la captación de plusvalías no están adaptados para ese fin. Es decir, se registra tanto una carencia de criterios e instrumentos adecuados para dimensionar en términos económicos los beneficios resultantes, como también de estrategias para efectivizar su distribución y equidad en términos socio-territoriales.

En este caso particular estudiado, la Municipalidad de Rosario crea instrumentos de captación de beneficios del Desarrollo Urbano a través de la figura denominada "Uso del mayor aprovechamiento urbanístico", a través de la cual los actores beneficiados por las nuevas normas deben efectuar un aporte económico a modo de "precio compensatorio", que será derivado a un fondo para la construcción de diversas obras para beneficio público, ya sea en el mismo sector o en otro.

Sin embargo, es importante remarcar que estos instrumentos han sido desarrollados durante el transcurso de la ejecución del Plan Especial Puerto Norte - Fase II. Por lo cual, en las primeras unidades de gestión realizadas no fueron aplicados; y en el resto de las unidades, al encontrarse mayormente en curso, todavía no se puede medir su éxito - en relación a la equidad distributiva de los beneficios resultantes a toda la sociedad en su conjunto.

Además, es importante señalar que la mayor parte de las unidades de gestión proponen en sus proyectos condominios privados para clases de alto poder adquisitivo, en conjunto con sectores comerciales y de servicios de alta categoría. De manera que, si 
bien este Plan Especial se encuentra todavía en construcción, las rejas perimetrales de aquellas unidades ya terminadas recuerdan las barreras pertenecientes a las instalaciones ferroportuarias negadas durante tantas décadas.

La situación se agrava frente a la segregación social existente en este sector, dado que, por fuera de dichas rejas, estas unidades de desarrollo inmobiliario para clase alta y media-alta lindan con asentamientos irregulares y unidades habitacionales precarias, que simplemente han sido dejadas de lado en el desarrollo del proyecto general. Con lo cual, se agrava el escenario de desigualdad y exclusión que padecen estos grupos sociales.
De manera que, siguiendo a Cuenya (2004), del otro lado se ubican diversos actores perjudicados, entre los que se encuentran: los habitantes localizados en asentamientos irregulares dentro de las parcelas de renovación urbana -o sectores aledaños a las mismas-; los residentes del barrio en el cual se localiza el desarrollo del GPU, que frente a la suba de los valores del suelo, pueden ser afectados por procesos de gentrificación; y, los actores vinculados a actividades usuales del área, que cambia su dinámica tradicional por nuevas demandas.

Parecería, entonces, que los límites presentes en este sector urbano han cambiado

Figura 6 - Condominios privados junto a asentamientos irregulares
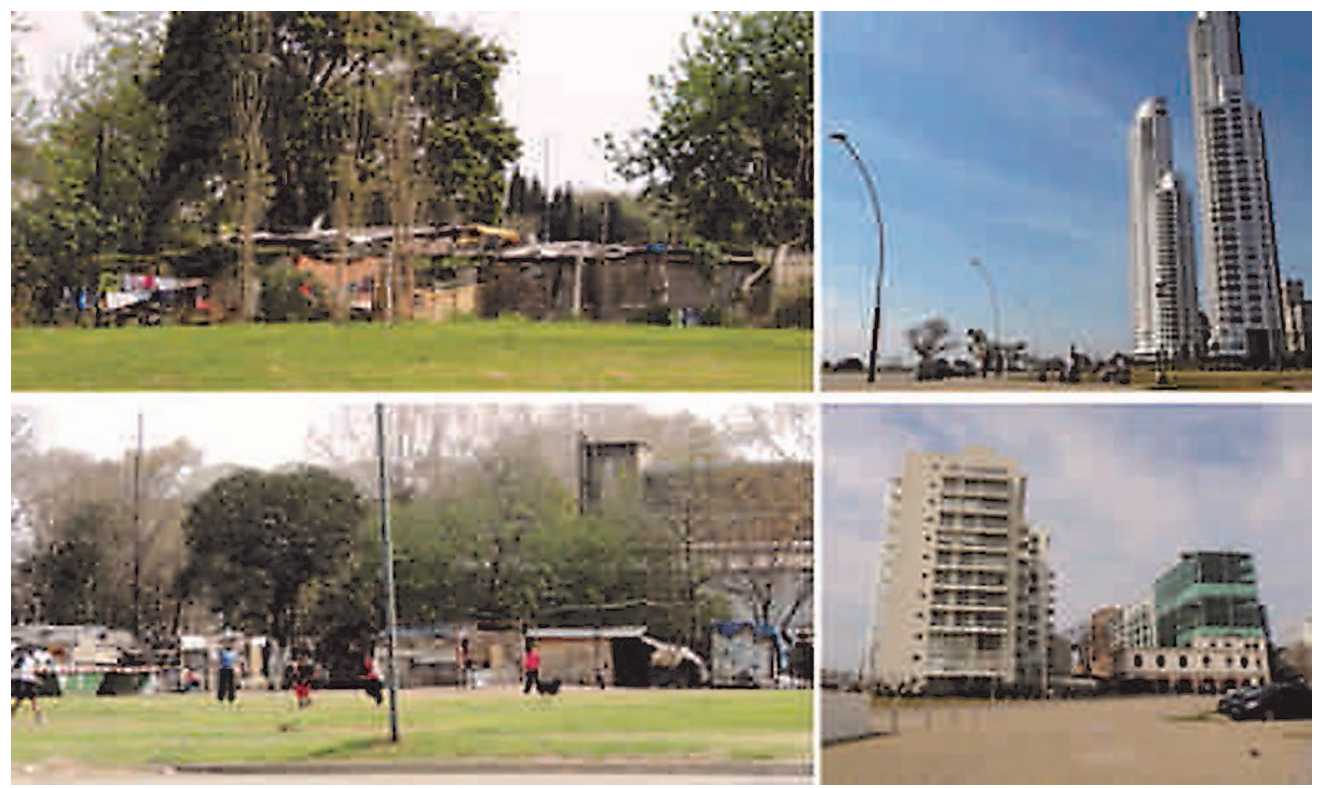

Fuente: Fotografías de la autora. 
de dueño y de nombre, pero siguen presentes, material e inmaterialmente, en el imaginario colectivo y en el reclamo por la apropiación de estas tierras para la sociedad en su conjunto. Frente a la realidad político-económica de Argentina en las últimas décadas, los modelos de "gestión empresarial" afrontados por parte de la administración pública lamentablemente tienden a profundizar la brecha entre las desigualdades urbanas y a contribuir a la fragmentación por sobre la articulación del territorio.

\section{Recuperación de espacios públicos}

Puerto norte se posiciona desde mediados del siglo XX en un tema de reclamo continuo de parte de diversos actores que solicitan recuperar el frente fluvial y grandes áreas urbanas centrales para uso público, a fin de restituir el anhelado diálogo con el río Paraná. Este reclamo se registra tanto desde el público en general, como en los instrumentos técnicos de planificación estatal. La sucesión de planes urbanos desde 1952 así lo registra. Como propone el Plan Director de 1999:

La renovación de Puerto Norte es una aspiración histórica y representa una de estas oportunidades a las que un Plan debe estar atento, y porque también significa el lugar capaz de catalizar el ideario colectivo de recuperación de la costa y modernización de la ciudad (...) con paseos y avenidas junto a la costa, parques y ramblas sobre la barranca, donde descubrir una perspectiva inédita de la ciudad y el río. (Municipalidad de Rosario, 1999)
Sin embargo, el proyecto de Puerto Norte con el transcurrir de las décadas termina siendo absorbido por la maquinaria inmobiliaria especulativa. Gran parte del espacio destinado a usos recreativos propuesto en 1999 es posteriormente privatizado quedando dentro de las unidades de gestión mencionadas y, el espacio público resultante - con excepción del parque Scalabrini Ortiz -, en términos generales resulta una sumatoria de espacios intersticiales y de componentes viales, sin equipamiento apropiado a fin de garantizar una apropiación colectiva del mismo.

De manera que, en este caso de estudio los intereses privados tienden a producir una topofagia urbana del espacio público. Es importante remarcar que la recuperación cuantitativa de éste no asegura una verdadera publicidad ${ }^{9}$ del espacio. Producir espacio público requiere intencionalidad, proyecto, escucha atenta a las voces colectivas - de quienes eligen y se apropian del mismo cotidianamente. Es decir, su definición no se limita a aquello que no corresponde a la propiedad privada, sino que debe incluir intrínsecamente en su desarrollo al rol de la identificación territorial y al intercambio con el otro. Esta marginalización del espacio por sobre el poder de la especulación, como explica Alberto Magnaghi (2011) ha generado, por un lado, la hipertrofia de la funcionalidad y del tráfico operativo $y$, por el otro, la hipotrofia de las relaciones sociales y del habitar.

Si entendemos al espacio público como "un espacio simbiótico en el sentido que genera integración, articulación, encuentro y conectividad de los distintos"; lo cual se logra a través de dos determinaciones: 1) "Que le da 
Figura 7 - Rejas y reclamos de la transformación del Plan Especial de Puerto Norte
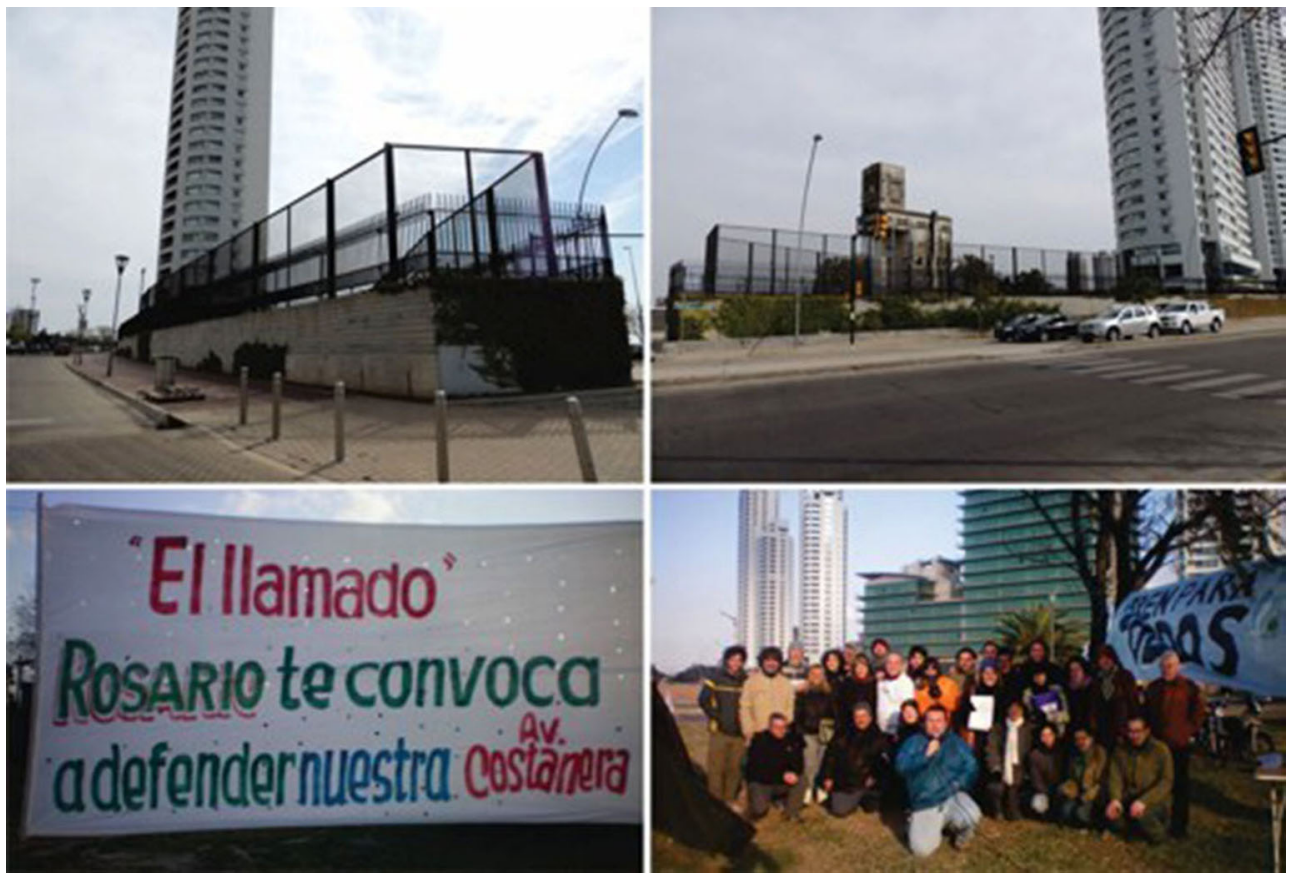

Fuente: Fotografías de la autora y argentina.indymedia.org

sentido y forma a la vida colectiva mediante la integración de la sociedad", y 2) "que le da un orden y unidad a la ciudad a través de su cualidad articuladora estratégica" (Carrión, 2005, p. 46); el rol del mismo y su producción debe resultar de atención prioritaria en el desarrollo de los GPU. Según exponen Borja y Muxi (2000), el espacio público debe garantizar la apropiación de diferentes colectivos sociales y culturales en términos de igualdad. A través de éste se define la calidad de la ciudad, la democratización de la misma. En este sentido, estos autores plantean que:

La paradoja de la ciudad de economía capitalista (Harvey) es que por una parte necesita el espacio público para su funcionamiento y para la gobernabilidad del territorio y por otro lo niega tendiendo a convertirlo en un espacio residual o "especializado" [...]. La separación espacio privado-espacio público y el dominio del primero sobre el segundo, la reducción de los espacios públicos a funciones monovalentes y la multiplicación de espacios segregados y privatizados de todo tipo son indicadores de una sociedad urbana clasista y desigual. [...] En consecuencia el objetivo común democrático de los gobiernos locales, de los movimientos sociales y de los profesionales del urbanismo es desarrollar políticas y proyectos que den prioridad al espacio público. (Borja y Muxi, 2000, p. 76) 
El sector de Puerto Norte representa una gran marca identitaria del territorio metropolitano. Siguiendo el pensamiento de Solá Morales (1996), consideramos que para actuar desde la arquitectura y el urbanismo en estos espacios, vacíos urbanos, es necesario partir de la escucha atenta de los flujos, las energías, los diversos ritmos que ha establecido el paso del tiempo y la pérdida de los límites. La ordenación urbana de estos ámbitos no puede consistir en una mera reordenación urbanística para que se integren nuevamente a la trama eficiente y productiva de la ciudad - aquella ciudad reglada de tanta libertad vigilada que se hacía referencia en el proyecto ganador del concurso nacional de ideas. Consideramos que de hacerlo, corremos el riesgo de cancelar el poder y la riqueza de la ausencia y el vacío. Por lo tanto, resulta necesaria una atención integrada, tanto desde las nuevas arquitecturas y la innovación como de los valores de la memoria, a fin de mantener viva la expresión urbana de este territorio. Sino, podemos caer en la tentación de convertir este lugar en otro.

\section{Políticas de preservación de los componentes productivos identitarios}

Los lineamientos de preservación resultan muy diversos y arbitrarios en este sector. Identificamos, a nivel general, tres modelos de protección patrimonial, ${ }^{10}$ o bien, tres modos de posicionarse frente al mismo: 1) El promovido desde el Estado como defensor de los bienes colectivos; 2) El que se encuentra en litigio entre la presión del mercado y el poder público, pero que prevalecen los criterios considerados a priori por éste último, y 3) El que el Estado cede ante la presión del mercado inmobiliario.

Se considera que forman parte del primer grupo, las propuestas de preservación cuyo leitmotiv consiste en conservar el patrimonio para las generaciones futuras a través de una respetuosa valorización de su existencia. Esto se logra a través de una mirada atenta al mismo en relación a su historia y a la identidad propia del territorio. Para lo cual, es necesaria la participación activa de todos los ciudadanos - y no sólo de técnicos o promotores inmobiliarios. Esto sucede cuando la propia comunidad se involucra en el reclamo de la valorización de las huellas territoriales. Por ejemplo, en el sector de estudio, se destaca la rehabilitación y puesta en valor del Complejo Arquitectónico Patrimonial "Parque Scalabrini Ortiz".11

En el segundo grupo se encuentran aquellas intervenciones en las que, si bien la presión del capital y del poder privado sea muy fuerte, el Estado prevalece en la definición de los lineamientos de preservación patrimonial. Resulta ejemplo de esto, la primera fase del Programa de Urbanización especial del Centro de Renovación Urbana Raúl Scalabrini Ortiz Área Talleres (Sector 4 - Distrito R5-2c). ${ }^{12}$

Finalmente el tercer grupo, comprende los casos de recualificación urbana en donde la presión del mercado inmobiliario arrasa con las huellas identitarias, las lógicas propias del barrio y sus habitantes. Es decir, se utilizan los recursos patrimoniales como una estrategia de marketing comercial. En estos casos se denota un débil accionar del Estado, ya que éste sucumbe a las demandas del privado. Por ejemplo, la reconversión urbana que sucede en las siete unidades de gestión del Plan Especial Puerto Norte. En 
Figura 8 - UG 2: Ciudad Ribera. Fragmentos a preservar
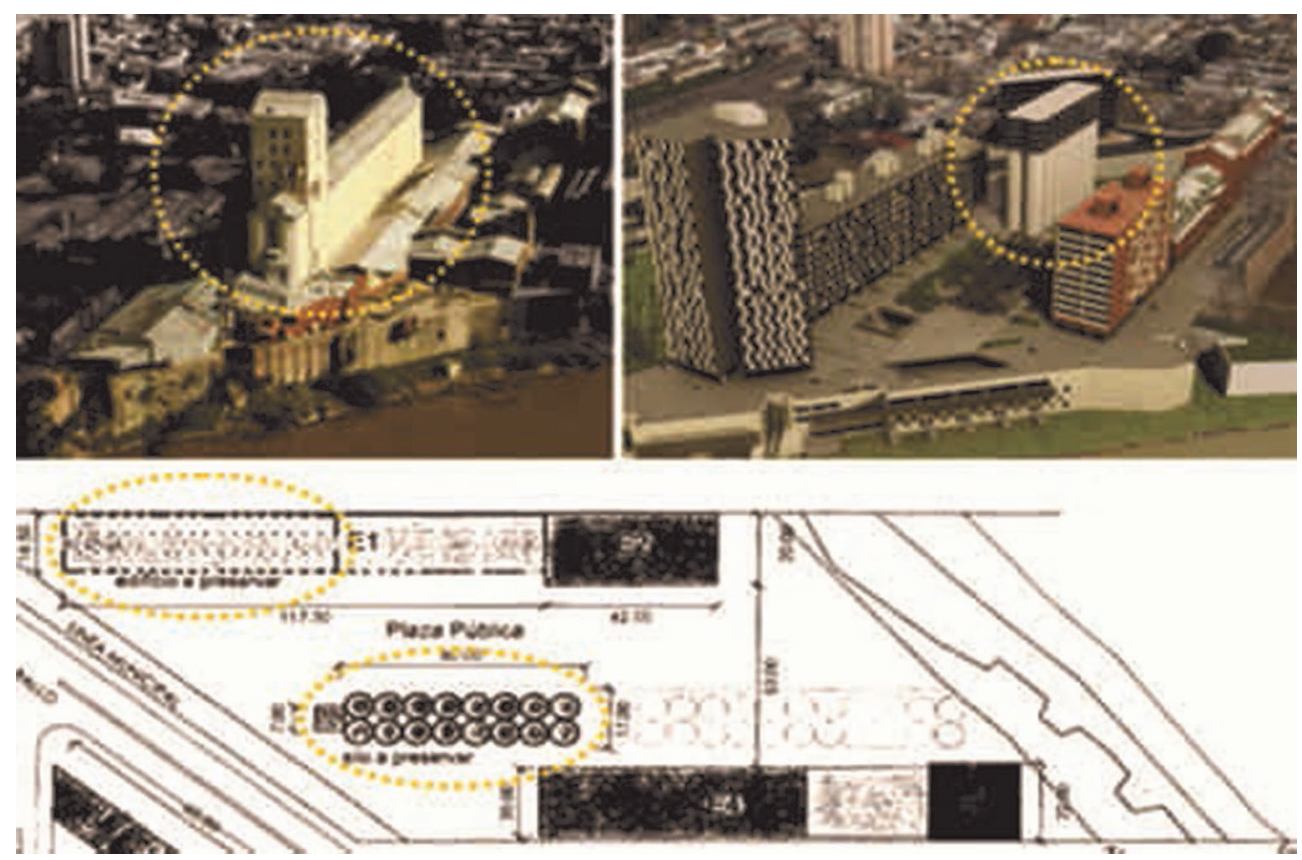

Fuente: Ordenanza $n^{\circ} 8.237 / 08$ - Municipalidad de Rosario.

Figura 9 - UG 2: Ciudad Ribera.

Fragmentos preservados - estado de situación año 2014
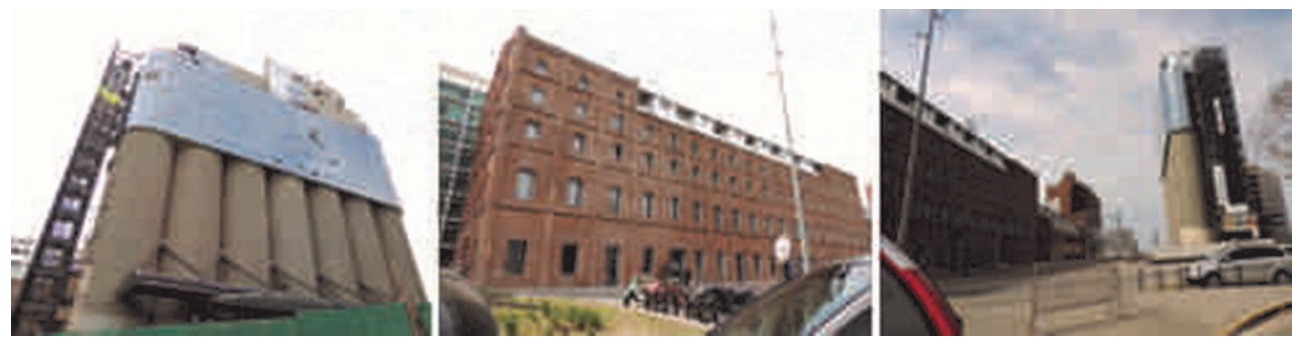

Fuente: Fotografías de la autora. 
este caso, el conjunto unitario existente de instalaciones productivas-portuarias resulta desmembrado, seccionado y demolido sectorialmente. Se dejan algunos fragmentos de algunos componentes edilicios históricos perdidos entre nuevas masas edificadas. Se "preservan" pequeños pedazos inconexos, inconclusos. Por ejemplo en la Unidad de Gestión $n^{\circ} 2$ - sector 2 llamada "Ciudad Ribera", se mantiene sólo un fragmento de los silos existentes en el predio, como también sólo una fracción de otra edificación considerada de valor patrimonial.

Estas políticas se avalan a través de la Ordenanza $n^{\circ} 8.237 / 08$, en la que a pesar de definir a este sector como Área de Preservación Histórica: "reconociendo en la suma de edificios de Valor Patrimonial un conjunto de gran significación histórica, donde se encuentren numerosos testimonios de los procesos productivos que se dieron en este sector de la costa", únicamente se considera la preservación de tramos discontinuos. Un tratamiento similar de preservación patrimonial se realiza en el resto de las unidades de gestión. Este accionar nos Ilama a reflexionar sobre nuestro legado histórico y sobre la presión del laissez-faire de la economía y de la predominancia de los intereses privados por sobre los bienes colectivos. El debate del significado de la revalorización patrimonial y sobre "¿qué estamos preservando?" debe ser un debate vivo, activo - no de puertas cerradas -, en el cual deben participar todos los actores de la sociedad y no sólo los grandes grupos económicos.

\section{Reflexiones finales}

Frente a los cambios acontecidos en las últimas décadas, vinculados a las dinámicas económicas, del mercado y la globalización, se producen transformaciones en las políticas públicas locales. Por ejemplo, en gran parte de las ciudades a nivel mundial se realizan reconversiones de áreas degradadas, localizadas en sectores estratégicos, con el fin de dar lugar a nuevos usos. Es así que la generación de nuevos condominios privados, para sectores de alto poder adquisitivo, resulta uno de los programas más elegidos en estas operaciones de renovación urbana, tal es el caso de Puerto Norte en Rosario. Si bien este sector es reclamado durante décadas por gran parte de la ciudanía - para la creación de nuevos espacios públicos -, el mercado inmobiliario finalmente se posiciona como motor principal en su transformación definitiva.

Ahora bien, ¿qué lecciones nos brinda este caso de estudio? ¿Qué aportes otorga al debate en torno a grandes proyectos de renovación urbana? Son diversas las temáticas, involucradas en el desarrollo del proyecto de Puerto Norte, que contribuyen a generar nuevas reflexiones en pos de mejorar los efectos resultantes de los GPU. Entre ellas podemos mencionar: a) el rol de los Concursos de Ideas y la importancia que éstos sean vinculantes al desarrollo del proyecto. Recordemos que, en este caso de estudio, se establecieron lineamientos contradictorios a los propuestos por el proyecto ganador, por ejemplo en 
relación a la preservación de la identidad del sector; b) la necesidad de profundizar los instrumentos de gestión, planificación y captación de plusvalías; y estudiarlos, como sus posibles efectos e impactos, a priori del inicio del desarrollo del proyecto; como también, focalizarse en la articulación de estas normas específicas con el resto de la normativa general de la ciudad. En Puerto Norte, la figura del Plan Especial se inserta generando una gran ruptura frente al resto de la ciudad donde se localiza; produciendo diversos impactos y efectos, gran parte de ellos negativos. Por este motivo, se considera necesario el estudio de los sectores de transición, buffer zone, con el fin de lograr una articulación urbana más armoniosa; c) la obligación de fortalecer el rol del Estado en todo el proceso, tanto en las definiciones proyectuales iniciales, como durante el proceso de desarrollo y ejecución. En este aspecto, resulta esencial la atención acerca del desarrollo de espacio público y de infraestructuras para beneficio de todos los ciudadanos y no sólo de aquellos vinculados específicamente al proyecto especial; d) incrementar el consenso, coordinación y participación multiactoral durante todo el proceso, escuchando todas las voces existentes en la ciudad; e) los Grandes Proyectos Urbanos, deben resultar atentos a la identidad del sector donde se localizan. Para lo cual, se requiere fortalecer estrategias de preservación de las marcas materiales e inmateriales existentes. Vemos que en Puerto Norte, se han tomado decisiones muy diversas respecto a esta problemática, algunas de escucha atenta a los sectores involucrados y otras más atentas a las presiones económicas.

Vemos entonces, que el poder del capital y las potenciales plusvalías urbanas influyen ampliamente en la definición y delineación de las políticas públicas. De manera que, la administración estatal se posiciona como medio posibilitante de la maquinaria especulativa inmobiliaria, cediendo ante la presión de los grandes promotores. Si bien el Estado aplica instrumentos de captación de plusvalías para beneficio público, los mismos no resultan suficientes para contrarrestar las problemáticas que suceden en las áreas lindantes a estos proyectos. A su vez, durante el desarrollo de la definición de las políticas a aplicar no se realiza un análisis crítico complejo que involucre los diversos temas y sectores, perjudicados y beneficiarios, que conforman la ciudad.

Se comprueba que, a pesar del aparente éxito de estos grandes proyectos de renovación - ya sea por la rehabilitación de sectores degradados, la generación de una nueva imagen de marketing urbana, la obtención de plusvalías, entre otros -, también se desencadenan diversos efectos negativos. Por lo cual, estos conflictos deberían ser previstos a través de un amplio y detallado análisis de los diversos temas claves tanto en las etapas de proyecto como de desarrollo. Los instrumentos de gestión no deben centrarse únicamente en la definición de indicadores edilicios, de usos, factores de ocupación del suelo y de las plusvalías resultantes. Sino, deben abordarse desde las 
problemáticas complejas y multisectoriales que implican los mismos, tanto a corto, mediano como a largo plazo.

En este sentido, resulta fundamental el papel activo y permanente de la participación pública y de todos los ciudadanos. No solo en la definición de las propuestas de transformación de la ciudad, sino en el reclamo y control del cumplimiento de los intereses colectivos. Ya que cuando el Estado es liderado por lógicas empresariales y pone en riesgo los recursos públicos, sólo el accionar social colectivo puede frenar y revertir procesos en curso.

\section{Cecilia Inés Galimberti}

Universidad Nacional de Rosario, Facultad de Arquitectura, Planeamiento y Diseño, Área de Teoría y Técnica Urbanística y Área de Historia de la Arquitectura. Rosario, Argentina.

cecilia.galimberti@gmail.com

\section{Notas}

(1) Por ejemplo: la Cervecería Quilmes, la Arrocera Argentina, la aceitera Santa Clara y posteriormente la Maltería SAFAC, en la ex Refinería de azúcar.

(2) Son tres las empresas ferroviarias que atraviesan este sector: Ferrocarril Córdoba/Rosario, Ferrocarril de la Provincia de Santa Fe y Ferrocarril Rosario/Buenos Aires.

(3) Por este motivo, la urbanización que surge en torno a estas instalaciones se denominan Barrio Refinería y Barrio Talleres.

(4) Como se establece en la Ordenanza $n^{\circ} 6.271 / 96$, se define a la primera fase del Desarrollo del Centro de Renovación Urbana Scalabrini Ortiz "al proyecto de urbanización de la vialidad primaria estructural, de los servicios y equipamientos urbanos concentrados y de los ámbitos públicos a crear que, sobre las áreas inicialmente disponibles, permita originar condiciones de nuevas centralidades urbanas y locales capaces de equipar y caracterizar en sus valores urbanos las sucesivas fases de desarrollo".

(5) Las instalaciones y vías ferroviarias existentes en este sector que incluyen Playa Balanza Nueva y Patio Cadenas, junto con la ya recuperadas de Talleres, el ahora Parque Scalabrini Ortiz, suman 148 Has.

(6) Las mismas se demarcan según siete polígonos y se las identifica como unidades de gestión, en función de la propiedad de la tierra o de las diferentes modalidades de organización entre propietarios, las cuales se aprueban en normas complementarias. 
(7) Responde a las asociaciones público-privadas que nos referíamos en los párrafos anteriores. Esta figura es un instrumento que formaliza el acuerdo entre la Municipalidad de Rosario y organismos públicos y/o actores privados o mixtos, para impulsar acciones de nueva urbanización, reconversión, reforma, renovación, rehabilitación y/o sustitución urbana.

(8) Se entiende por plusvalías urbanas a "la valoración del suelo que se genera durante el proceso de producción de los proyectos, en función de los cambios urbanísticos notables que tienen lugar en las áreas estratégicas donde ellos se localizan" (Cuenya, 2012, p. 14).

(9) Referido al carácter público del espacio.

(10) Es de remarcar que consideramos que las intervenciones que corresponden a uno u otro modelo no se definen ni por la propiedad jurídica del inmueble, ni por el grado de preservación propuesto. Es decir, no se considera que las obras que prácticamente no pueden modificarse corresponden al primero y las que se permite un alto grado de cambio forman parte del tercer modelo. Sino, se identifican estos modelos en relación a qué es definido patrimonio y cómo es tratado este recurso en pos del beneficio de toda la población.

(11) Se destaca la refuncionalización de los ex talleres del Ferrocarril Central Argentino en un nuevo complejo educativo en los que se localizan la sede de la Regional VI del Ministerio de Educación y los talleres de las escuelas técnicas $n^{\circ} 471$ y $n^{\circ} 467$. Este proyecto ha sido realizado desde una mirada sensible a las marcas patrimoniales. Si bien se readapta a nuevos usos, en relación a las necesidades actuales de la población, se ha restaurado respetando las lógicas propias de los componentes. Es decir, la nueva construcción no interviene en los muros existentes en la inauguración de los talleres; se restauran todas las fachadas conservando las aberturas originales; se readecuan los accesos reinsertándolos en la trama urbana, pero respetando la jerarquización del conjunto edilicio; se pone en valor la totalidad de la estructura metálica original; entre otras acciones. Es de remarcar que aún se encuentran en curso diversos proyectos de rehabilitación patrimonial de este complejo; por ejemplo, el plan de revalorización del denominado barrio inglés, a través del cual se plantea restaurar los edificios residenciales del Batten Cottage y el Morrison Building.

(12) Este sector urbano, perteneciente al Estado nacional, es adquirido por firmas privadas, Alto Palermo S.A. y Coto C.I.C.S.A, a fin de realizar un centro comercial. A pesar de las disputas en torno a las demandas del privado versus los lineamientos planteados por el Estado, éste último define previamente las políticas de intervención y los componentes patrimoniales a restaurar y preservar.

\section{Referencias}

BORJA, J. e MUXI, Z. (2000). El espacio público, ciudad y ciudadanía. Barcelona, Electa.

BRUTTOMESSO, R. (1993). Waterfronts. A new urban frontier for cities on water. Veneza, Centro Internazionale Citta d'acqua.

CARRIÓN, F. (2005). "El centro histórico como objeto de deseo". In: CARRION, F. y HANLEY, L. (eds.) Regeneración y revitalización urbana en las Américas: hacia un Estado estable. Quito, Flacso. 
CASTELLS, M. e BORJA, J. (2000). Local y Global. México, Santillana Ediciones Generales.

CICCOLELLA, P. (2011). Metrópolis latinoamericanas: más allá de la globalización. Quito, Olacchi.

CUENYA, B. (2009). Grandes proyectos urbanos latinoamericanos. Aportes para su conceptualización y gestión desde la perspectiva del gobierno local. Cuaderno Urbano. Espacio, Cultura, Sociedad, v. 8 , n. 8 , pp. $229-252$.

(2012). Grandes proyectos urbanos. Miradas críticas sobre la experiencia argentina y brasileña. Argentina, Café de las ciudades.

DE MATTOS, C. (2008). “Globalización, negocios inmobiliarios y mercantilización del desarrollo urbano". In: HIDALGO, R. y PEREIRA, P. Producción inmobiliaria y reestructuración metropolitana en América Latina. Serie GeoLibros. Santiago de Chile, Instituto de Geografía UC.

GALIMBERTI, C. (2015). La reinvención del río. Procesos de transformación en la ribera de la Región Metropolitana de Rosario, Argentina. Colección Tesis Doctorales n. 2. Rosario, UNR Editora.

GARCÍA CANCLINI, N. (2008). La globalización imaginada. Buenos Aires, Paidós.

GARCÍA DELGADO, D. (1994). Estado y sociedad. La nueva relación a partir del cambio estructural. Buenos Aires, Tesis-Norma.

HAESBAERT DA COSTA, R. (2011). El mito de la desterritorialización: del "fin de los territorios" a la multiterritorialidad. México, Siglo XXI.

LUNGO, M. (2005) Globalización, grandes proyectos y privatización de la gestión urbana. Revista Urbano, v. 8, n. 11, pp. 49-58.

MAGNAGHI, A. (2011). El proyecto local. Hacia una conciencia del lugar. Barcelona, ArchitectonicsUPC.

MUNICIPALIDAD DE ROSARIO (1967). El Plan Regulador Rosario. Rosario.

(1999). Nuevo Plan Director, bases para el Acuerdo. Rosario, Secretaría de Planeamiento.

(2011) Libro PUR: Plan Urbano Rosario 2007-2017. Rosario, Secretaría de Planeamiento.

MUNUCE, J. (2004). Concurso Nacional de Anteproyectos e ideas para la definición del Plan General para la segunda fase del Centro de Renovación Urbana Scalabrini Ortiz. Memoria descriptiva del proyecto ganador. Rosario. [Mimeo]

SOLÁ MORALES, I. (1996). “Presente y futuros. La arquitectura en las ciudades”. In: AA. VV. (1996) Presente y futuros. Arquitectura en las grandes ciudades. Barcelona, Col.legi Oficial d'Arquitectes de Catalunya / Centre de Cultura Contemporània.

SVAMPA, M. (2001). Los que ganaron. La vida en los countries y en los barrios privados. Buenos Aires, Biblos.

VAINER, C. (2012). “Grandes proyectos urbanos. ¿Qué son y cómo evaluarlos?”. In: CUENYA, B. (comp.). Grandes Proyectos Urbanos. Miradas críticas sobre la experiencia argentina y brasileña. Argentina, Café de las ciudades. 
